\title{
Como se Sentem Pacientes Quando Examinados por Estudantes de Medicina? Um Misto entre Ambiguidades e Satisfações Encontradas em Estudo Qualitativo
}

\author{
How do Patients Feel when Examined by \\ Medical Students? \\ A Cross Between Ambiguities and \\ Satisfaction Found in a Qualitative Study
}

Alcir Escocia Dorigatti ${ }^{I}$

Eliel Wagner Faber

Celso Garcia Junior ${ }^{2}$

Egberto Ribeiro Turato

PALAVRAS-CHAVE

- Educação Médica;

- Visitas com Preceptor;

- Hospitais de Ensino;

- Pesquisa Qualitativa;

- Anamnese.

\section{KEYWORDS}

- Medical Education;

- Teaching Rounds;

- Teaching Hospitals;

- Qualitative Research;

- Medical History Taking.

Recebido em: 07/09/2013

Reencaminhado em: 01/10/2014

Aprovado em: 07/10/2014

\section{RESUMO}

No contexto do ensino médico, pacientes são habitualmente convidados a colaborar se submetendo ao exame clínico para serem observados. Como pacientes se sentem nessa situação? Para discutir significados psicológicos atribuídos a esta experiência, usamos o método clínico-qualitativo, conduzido com amostra intencional de dez pacientes de um hospital público de ensino, com entrevistas semidirigidas de questões abertas em profundidade. Os resultados foram interpretados segundo conceitos tradicionais da Psicologia Médica. Pacientes manifestam uma relação um tanto ambígua com os alunos, às vezes fortalecendo a relação médico-paciente-equipe, outras vezes a desconstruindo. A presença dos alunos é importante devido ao vínculo gerado, mas pode originar dúvidas sobre como lidar com situações mobilizadoras. As construções sociais são diferentes em um hospital de ensino em comparação com outros hospitais, visto que naqueles os pacientes têm um papel de agentes educadores. Pacientes podem perceber essa dinâmica, ainda que com pouca sistematização, ou não ter qualquer consciência social.

\section{ABSTRACT}

As part of medical training, patients are often invited to cooperate by allowing student observation of their medical examination. How do patients feel in this situation? To discuss the psychological meanings assigned to this experience we used the clinical-qualitative study method on an intentional sample of 10 patients from a teaching hospital, using in-depth semi-directed interviews. The results were interpreted according to concepts of Medical Psychology. We found that patients have an ambiguous relationship regarding the students. For example, the presence of students sometimes strengthens the doctor-patient-team relationship, but sometimes might undermine it. Student presence is important due to the bond generated, but students may act indecisively when dealing with certain situations. The social constructions within a teaching hospital differ to those in other hospitals, since in the former the patients also act as an educational agents. Some patients are aware of this dynamic albeit without it being systemized, whereas others display no such social awareness. 


\section{INTRODUÇÃO}

Sabemos que a satisfação do paciente com o atendimento oferecido durante a internação em hospital-escola não é influenciada de forma negativa pela presença dos estudantes de Medicina durante a consulta, quando comparada com uma consulta onde não há alunos ${ }^{1}$. Na realidade, estudos mostraram que $95 \%$ dos pacientes têm uma atitude positiva ou mesmo neutra em relação à presença do estudante ${ }^{2,3}$. A aceitação da presença de estudantes diminuiria quando o paciente procura atendimento por problemas emocionais, sexuais ou quando um exame físico íntimo é necessário².

Pilares do ensino-aprendizado médico são a entrevista clínica e o exame físico ${ }^{4,5}$. Em vários momentos, na rotina dos diversos cursos de graduação da Faculdade de Ciências Médicas, os alunos são chamados a abordar os pacientes internados no Hospital das Clínicas, com os reconhecidos objetivos de obter uma entrevista médica, examiná-los e realizar procedimentos. Sabemos que alunos não têm o papel legal de estabelecer diagnósticos e preconizar tratamentos a esses pacientes, nem como "coautores" do médico assistente e do docente, visto que, em atividades didáticas das disciplinas de Semiotécnica da Observação Clínica e de Semiologia e Propedêutica - ambas obrigatórias para alunos de Medicina do terceiro ano -, este grupo interage com os hospitalizados com alvo de ensino. Nessa abordagem, pacientes são convidados a permitir que sejam examinados do ponto de vista médico, iniciando-se no ritual histórico da demonstração da técnica pelo professor, quando, então, os alunos repetem, um a um, aquela prática semiológica.

A condição de pessoas internadas, tal como reconhecida, é de fragilidade física e emocional, representando um momento crítico para elas ${ }^{6}$. Sua percepção a respeito do processo saúde-doença interfere fortemente no cuidado que os profissionais de saúde lhes oferecem. Uma abordagem satisfatória requer a criação de vínculo pessoal, não fugaz, com o profissional atendente e com toda a equipe responsável pelo tratamento.

Como se sentiria o paciente diante deste ritual do hospital-escola? Um estudo conduzido por uma universidade catarinense com 43 pacientes mostrou apenas uma manifestação de sentir-se envergonhado em responder a perguntas da entrevista, e dois pacientes declararam que o exame físico havia sido cansativo, enquanto 18 disseram ter ficado satisfeitos pela participação naquela atividade ${ }^{7}$. Por outro lado, em um estudo da Faculdade de Medicina de Botucatu, no qual 25 pacientes foram avaliados, o único item não unanimemente tido como bom ou ótimo foi a "aula em torno do leito". Um paciente referiu sentir-se como "bicho na gaiola", ainda que a visita médica fosse considerada boa e necessária. Como esperado, os autores do estudo postulam que o sentimento de gratidão pelo atendimento prestado leva os pacientes a superar eventuais situações desagradáveis às quais teriam sido expostos ${ }^{8}$.

Em estudo sobre visita médica em hospital universitário, a maioria dos pacientes classificou a visita de ensino como boa, a despeito de comentários do tipo "há falta de informação sobre a atividade", "sentir-se como cobaia", "objeto de estudo" ${ }^{\prime \prime}$. Não obstante, um estudo realizado com 209 pacientes em hospital privado sem fins de ensino, em Brasília, mostrou que $57 \%$ deles gostariam da presença de estudantes de Medicina durante a consulta por acreditarem que receberiam atenção e cuidados especiais. Por outro lado, $67 \%$ se sentiriam mais seguros se estivesse presente o médico residente em vez dos alunos. Tais resultados sugerem que, mesmo em hospital privado não escola, haveria aceitação da presença de estudantes de Medicina ${ }^{10}$. É distinta a opinião dos pacientes sobre a participação de alunos, embora pareça haver uma homogeneidade na opinião a respeito da ocorrência de visitas médicas para algum tipo de ensino.

Assim, para melhor compreender sentimentos e percepções de pacientes internados em diversas enfermarias do HC Unicamp e, com os resultados do trabalho, poder aprimorar uma interação harmoniosa com pacientes neste papel, construímos o alvo da presente pesquisa.

No levantamento da literatura, não encontramos textos que focassem a investigação qualitativa exclusivamente por meio de relatos não dirigidos sobre a experiência de doentes internados em hospital universitário brasileiro a partir de hipóteses diversificadas enquanto sujeito do aprendizado.

O escopo deste artigo é discutir, do ponto de vista psicológico, os significados atribuídos por pacientes internados em diversas enfermarias do HC/Unicamp às próprias percepções e vivências enquanto sujeitos do aprendizado de alunos de Medicina em atividades didáticas de semiotécnica médica.

\section{SUJEITOS E MÉTODOS}

\section{Campo de pesquisa}

O HC/Unicamp atende cerca de 13.600 internações a cada ano. É um hospital-escola vinculado à Faculdade de Ciências Médicas (FCM) e constitui o principal local de aprendizado e pesquisa, para alunos tanto de graduação, como de pós-graduação em sentido amplo e estrito junto à instituição. Sendo um hospital público vinculado ao SUS, é também referência de complexidade para uma região de mais de quatro milhões de habitantes, contando com enfermarias, ambulatórios e pronto-socorro para diversas especialidades clínicas e cirúrgicas ${ }^{11}$. 


\section{Sujeitos da pesquisa}

O grupo de entrevistados foi construído por amostra proposital, ou seja, foram convidados intencionalmente pacientes internados em diversas enfermarias do $\mathrm{HC} /$ Unicamp que concordassem em participar relatando suas experiências. Os critérios de inclusão contemplaram os que já haviam recebido visita dos alunos do curso médico para atividades das disciplinas de semiologia/semiotécnica médica, que se dispuseram a colaborar com seus relatos mediante assinatura de um termo de consentimento e que apresentavam condições clínicas, intelectuais e emocionais que permitissem discursos fidedignos. A amostra foi fechada por saturação teórica das informações ${ }^{12}$, isto é, foram entrevistados sujeitos sucessivamente até que as falas se tornassem repetitivas e, assim, consideradas suficientes para uma discussão consistente com resultados plausíveis, de modo a responder às hipóteses levantadas, segundo a avaliação do pesquisador - primeiro ator deste artigo - e validada em supervisão com o orientador - último autor - e coautores, bem como em reunião com os pares revisores do grupo de pesquisa a que estão todos filiados.

\section{Recursos metodológicos}

$\mathrm{O}$ roteiro que norteou as etapas da pesquisa foi o Método Clínico-Qualitativo (MCQ) ${ }^{13,14,15}$. Tal como os métodos qualitativos "genéricos" trazidos das Ciências Humanas, o MCQ almeja interpretar os significados que sujeitos estudados dão a fenômenos vivenciados, sendo aplicado particularmente a settings assistenciais, que privilegiam três atitudes: existencialista (postura de valorização das inquietações naturais das pessoas envolvidas frente a questões humanas vivenciadas); clínica (no sentido de o pesquisador inclinar seletivamente sua escuta e olhar quem está naturalmente incomodado com suas angústias frente à saúde); e psicodinâmica (postura que busca valorizar os afetos presentes e trocados numa entrevista pessoal enquanto elementos intervenientes no discurso).

A viabilização ocorre com o emprego da técnica da Entrevista Semidirigida de Questões Abertas, iniciada com breve coleta de dados pessoais do informante, em que se estabelece o rapport ${ }^{16}$. Na entrevista psicológica conduzida em profundidade, o pesquisador introduziu o tema da pesquisa com a seguinte questão disparadora: “O(A) senhor(a) está internado num hospital-escola, onde há estudantes de Medicina. Conte como é esta experiência de ser entrevistado e examinado por alunos". A partir daí, o entrevistado dirige sua fala, respeitando-se sua livre associação de ideias. Eventuais interposições do entrevistador visam encorajar o informante a aprofundar ou esclarecer pontos percebidos como pouco explorados na fala.

\section{Diário de campo e procedimentos de aplicação do instrumento}

Ainda como instrumento para a coleta de dados, empregamos a entrevista psicológica mencionada, bem como um diário de campo, recurso nos moldes do antropólogo que anota as ocorrências em suas idas a campo. A captação da amostra ocorreu com o conhecimento e aval dos médicos e enfermeiros responsáveis pela respectiva enfermaria. As entrevistas foram conduzidas pelo primeiro autor do artigo, com auxílio de gravador de voz para registrar os dados com maior fidelidade. $\mathrm{O}$ entrevistador procurou horários que não colidissem com atividades/tarefas/procedimentos do serviço. Sempre que possível, buscou-se levar o paciente a um recinto próximo a seu leito onde houvesse ambiente reservado.

\section{Tratamento dos dados e quadro de referencial teórico}

O conjunto de entrevistas foi transcrito na íntegra e submetido à técnica de análise qualitativa de conteúdo, entendida como a etapa inicial das releituras flutuantes, isto é, feitas com manejo de expectativas a fim de que os pesquisadores tangenciassem o texto para se deixar impregnar pela tonalidade afetiva e pelo subjacente ao discurso dos entrevistados. Nessa análise, dados originais podem ser encontrados ao não se ocupar da materialidade das respostas, buscando nas entrelinhas ou no não dito os núcleos de sentidos das vivências da realidade do paciente - no caso, em sua interação com os aprendizes de medicina. O enfoque psicodinâmico na interpretação de recortes do discurso desvela, por exemplo, mecanismos emocionais defensivos ou adaptativos.

Com a emergência de núcleos de sentido ao longo do conjunto das entrevistas, temos a categorização, isto é, tópicos para discussões que satisfizessem a revisabilidade das hipóteses levantadas. Os pesquisadores procuraram respeitar a perspectiva êmica que marca os métodos qualitativos: a discussão se esforça por ser feita na visão dos informantes. Os pesquisadores tiveram ainda em mente o caráter polissêmico dos achados, marca das Ciências Humanas, que entendem que fenômenos vivenciados vêm carregados de múltiplos sentidos atribuídos. Na discussão dos resultados, os autores tiveram como quadro teórico de ancoragem conceitos consagrados da disciplina de Psicologia Médica, sobressaindo concepções psicodinâmicas aplicadas à compreensão das relações entre pessoas participantes dos settings do atendimento assistencial em saúde, bem como a identificação de mecanismos reativos e adaptativos às situações sob consideração.

\section{Aspectos éticos}

O projeto foi aprovado pelo Comitê de Ética em Pesquisa com Seres Humanos, da Faculdade de Ciências Médicas da Unicamp, protocolo 155/2011, contendo o Termo de Consentimento para Participação de Pacientes em Pesquisa Psicológica. 


\section{RESULTADOS E DISCUSSÃO}

Foram selecionadas para este artigo duas categorias de discussão, comentadas a seguir.

\section{Ganhos e perdas gerados pela presença dos alunos}

Ao contrário do que o senso comum levaria os estudantes a crer, há pacientes que não entendem a visita de ensino como algo constrangedor, mas como uma porta para construções vivenciais diferentes das que comumente experimentam em um hospital. Na fala seguinte, curiosamente, o entrevistado menciona o inverso:

"Eu acho que o constrangimento, no caso, deve ser um pouco maior por parte do aluno!" (E1)

Dificuldades na relação paciente-aluno provêm naturalmente da inexperiência de abordagem por parte dos estudantes, iniciantes nos estudos da arte da clínica. Com base na observação relatada, cogitamos que o informante possa ter percebido que os alunos apresentam uma atitude emocional defensiva frente à experiência nova na relação examinador-examinando.

Por um lado, os pacientes se encontram em situação normal de fragilidade, submetidos aos cuidados da equipe hospitalar; por outro, sentimentos previsíveis de insegurança por parte de alunos podem ser percebidos pelos pacientes. Tal como receber cuidados de quem ainda "não sabe o que está fazendo" ou, então, que a equipe estaria "perdida" diante de sua condição clínica, já que pacientes podem não se voltar para a figura de um aluno, mas, sim, para a de um cuidador capacitado. Vejamos:

"Acho que ela não fica envergonhada, né? Porque, como é a profissão dela, ela não pode sentir vergonha por mim, nem eu por ela". (E2)

Uma situação interessante acontece quando o aluno ainda não está apto a estabelecer um vínculo harmonioso com os pacientes, o que, algumas vezes, pode ser facilitado por estes, notadamente por pacientes com mais idade que os aprendizes, numa atitude paternalista. Tais percepções são comumente moduladas pelas vivências emocionais e pela estrutura de personalidade dos pacientes. Cogitamos se seria verdade ou mito que pacientes de maior nível de escolaridade teriam mais facilidade de lidar com novidades no ambiente, tal como a presença de alunos examinadores, quando comparados a pacientes de profissões tidas como mais humildes.
Outro fenômeno relevante que modularia a percepção dos pacientes frente à presença dos alunos seria o contexto social de origem. Por exemplo, questionamos se pacientes advindos de pequenas cidades teriam mais dificuldade em reagir com mais naturalidade às repetitivas anamneses e exames físicos que ocorrem durante sua internação em hospital-escola. Aspectos culturais em que foram criados exigem, por exemplo, uma complexa crença do "resguardo do corpo". Em caso de haver insuficiência nos cuidados, essa situação geraria nos pacientes um possível desconforto de ser "descoberto", procurando, por conseguinte, "adivinhar" o que o médico quereria ouvir, fornecendo informações distorcidas como compreensível defesa do próprio constrangimento.

Por outro lado, entendemos que o aluno precisa ter uma percepção individualizada das respostas verbais e manifestações não verbais dos pacientes, para moldar a relação clínica e de aprendizado de forma mais harmoniosa e, assim, expandi-la para a equipe. Num entendimento estrutural, se um aluno, dispondo de mais tempo para estar com o paciente, construísse uma relação tipicamente forte com ele, essa experiência seria irradiada a toda a equipe, já que o paciente colocaria o aluno como igualmente constituinte da equipe. Entretanto, se o aluno interagir de forma distônica, isto pode igualmente se difundir do paciente para toda a equipe, desfavorecendo certa harmonia grupal.

Há situações em que o paciente utiliza a primeira abordagem do aluno para representar barreiras da timidez deste aprendiz:

\footnotetext{
"Mas a pessoa chega tímida aí... O que eu vou fazer? Vou conversar, mas como que eu vou puxar assunto? Ele é que teria que puxar assunto, né? Mas a gente fica com vergonha". (E5)
}

A frequente inibição de determinados estudantes no início de seu treinamento terá sido vista com maus olhos pelo paciente se for notada certa falta de franqueza do aluno na relação. Talvez não haja desconforto significativo para os pacientes em saber que o aluno está fazendo sua primeira entrevista clínica ou ainda não sabe dar explicações às demandas dos pacientes, mas pensamos que esse fenômeno seja apreendido em algum grau.

\section{O paradoxo de Escher - a relatividade do processo educacional}

O homem, enquanto ser social, é levado ao convívio comunitário, com a inserção e aceitação pela comunidade em determinado tempo e espaço. A inserção na comunidade é concer- 
nente aos papéis sociais desempenhados pelos indivíduos e às inter-relações entre eles. Certa pessoa se sentirá integrada ao meio em que vive quando encontrar para si os papéis sociais a serem satisfatoriamente desempenhados. O não reconhecimento de um papel em exercício ou o não enquadramento social pode levar a uma anomia. Quando se alteram os pares participantes de uma comunidade, bem como o lugar social onde um indivíduo será inserido, pode ocorrer um choque cultural, assim como com os novos papéis assumidos nesse novo ambiente, ainda em acolhimento para o indivíduo "importado".

A beira do leito hospitalar é o lugar clássico de encontro entre o paciente assistido pela medicina e a figura do médico, investido de autoridade científica, representante da medicina universal ${ }^{17}$. Entendemos que, no contexto do hospital-escola, esta concepção se expande com a presença dos estudantes, contribuindo de forma positiva no momento de fragilidade vivenciado pelo paciente, como podemos observar na fala:

\footnotetext{
"Eu gosto de conversar! Porque é bom, né? Tira as coisas da cabeça! Sabe, às vezes você põe as coisas na cabeça? Um dia eu cheguei a perder três noites de sono sentada no sofá, com coisas na cabeça. É uma pena, não é? Então é bom porque você está se distraindo! Às vezes, pensa só o que não presta! Eu acho que conversar é bom, é muito bom!" (E10)
}

O processo de adoecimento e hospitalização traz sentidos nesse contexto teórico, considerando o paciente retirado de suas vivências habituais e conduzido a experimentar o ambiente hospitalar. Neste novo enquadramento - uma comunidade hospitalar passageira -, o paciente se encontra sem suas referências habituais e percebe os novos papéis que comumente não vivencia fora. Inicia-se, assim, para o paciente, a busca do que seja a "identidade do hospitalizado" e o que isso representaria simbolicamente para si e para o outro - no caso, o pessoal da equipe de saúde.

A internação pode ser marcada como um corte na biografia do paciente hospitalizado - uma ruptura provocada pela suspensão do cotidiano e pelas novas vivências de pessoa sob cuidados específicos. Temor da morte em potencial, distanciamento do universo habitual, separação em relação aos familiares - estes fatores de fragilização contribuem para reorganizar as percepções do paciente, expandindo-as e fomentando reflexões de um ponto vista que não era vivenciado: o estar dependente dos médicos e enfermeiros. Podemos observar isto na seguinte fala:

"A gente só encontra depois que entra num negócio desses, fica internado! Eu tive alguns colegas, que assim... Só ago- ra eu estou encontrando. Então está sendo muito bom esse negócio aqui, porque eu estou tendo a oportunidade - volto a falar oportunidade! - de poder ficar comigo mesmo, estar lendo mais, poder refletir". (E1)

"A internação representa você estar sem poder dar rumo na sua vida!" (E8)

Diferentemente da situação que os pacientes vivenciam em hospitais comuns, onde são atendidos por determinados médicos, em hospitais-escola costuma haver uma equipe maior empenhada no tratamento desses pacientes, em cuja abordagem se destaca a transmissão do conhecimento médico aos aprendizes. A ruptura social gerada pela entrada na realidade intra-hospitalar, por si, já causa um compreensível estranhamento, desencadeando naturais ansiedades e medos, acentuando fragilidades dos pacientes. Entretanto, quando o local de internação é um hospital-escola, percebe-se um estranhamento adicional dos pacientes, por não estarem acostumados à rotina da presença de estudantes que têm suas dinâmicas pedagógicas de aprendizagem em enfermarias. Eventuais reclamações frente a este setting mais complexo podem se manifestar de modo subliminar. $\mathrm{O}$ enquadramento do paciente internado em hospital-escola pode fazê-lo ressentido, por exemplo, frente a horários disputados para tantas tarefas, ressaltando-se, contudo, um grau de aceitação associado à gratidão pelo tratamento recebido:

"Às 5 h30 da manhã estão trabalhando, elas davam risada, embora algumas estivessem também abrindo a boca, mas estavam alegres! E eu sei que elas não ganham tanto dinheiro pra isso, então é realmente uma coisa maravilhosa!" (E1)

Em sua nova posição, na hierarquização do ambiente hospitalar, o paciente se localizaria como detentor de um poder pouco notado: o de ser "material" do qual provém o saber médico para os aprendizes, embora ele normalmente não tenha consciência dessa condição. É lícito dizer que pacientes são fontes do saber, já que os profissionais de saúde aprendem muito na relação direta com o doente. Por conseguinte, os pacientes adquirem grande poder, pois apenas por meio do trabalho com eles é que os futuros médicos irão alcançar a formação como clínicos. É relevante frisar que esta consideração sobre poder se refere ao ponto de vista dos acadêmicos; para o paciente, o fato de propiciar ou não o aprendizado não seria uma prioridade, já que supostamente ele deseja obter melhora clínica. Desta forma, os pacientes têm dupla importância para o meio acadêmico, por significarem a consolidação, em uma única pessoa, tanto do receptor da cura dada pelo médico, como do doador de aprendizado aos futuros médicos. 
Como nas famosas pinturas das escadarias de Escher, dentro de um hospital-escola não há, em tese, uma inquestionável hierarquização de relações humanas. Aos olhos do paciente, o aluno, enquanto membro da equipe, pode ser provedor de suas demandas existenciais, sendo aquele que o ajudará, um dia, a alcançar o que deseja: a cura. Por sua vez, os alunos têm no paciente uma fonte de conhecimentos, bem como a oportunidade de exercitá-los segundo os nobres princípios desejáveis na escolha da medicina: ajudar o próximo, vencer a dor, minorar sofrimentos. Assim, o que ocorre seria uma simbólica não verticalização, cada um podendo conceder importância ao outro - um terreno fértil para a construção de uma relação médico-paciente harmoniosa e eficaz.

\section{CONCLUSÕES}

Nossos comentários finais não devem ser generalizados a priori a situações semelhantes, visto que o modelo da pesquisa qualitativa não autoriza aplicar resultados dessa forma. Pontuamos os limites do estudo realizado: o método qualitativo, por estudar em profundidade a particularidade, almeja gerar novos conceitos a partir da compreensão de significados ali relatados. A aplicação é a posteriori, quando o leitor/consumidor da investigação concluída verá se os resultados trazem luz à compreensão de um novo enquadramento que então se desenha à sua frente.

Os autores entendem que o conjunto de categorias desta pesquisa revelou que as percepções são naturalmente ricas e complexas, e que os conteúdos presentes na relação aluno-paciente são mais amplos que discursos anamnésticos. Fragilidades físicas e emocionais dos pacientes não necessariamente inibem reflexões sobre vivências "intra-hospitalares". Costuma haver um senso comum de que os pacientes focam principalmente a experiência da doença e não "estariam com cabeça" para outros focos, importando a eles, sobretudo, a cura. Embora esta possa ser sua prioridade, os pacientes percebem e refletem sobre o meio em que se inserem nesta realidade do hospital-escola. Por conseguinte, é relevante o debate sobre estes fenômenos também por parte dos cuidadores profissionais, em vista de sua atenção integral à busca de melhor saúde do paciente.

\section{REFERÊNCIAS}

1. Benson J, Quince T, Hibble A, Fanshawe T, Emery J. Impact on patients of expanded, general practice based, student teaching: observational and qualitative study. BMJ. 2005; 331(7508):89.

2. O'Flynn N, Spencer J, Jones R. Consent and confidentiality in teaching in general practice: survey of patients' views on presence of students. BMJ. 1997; 315(7116):1142.
3. Cooke F, Galasko G, Ramrakha V, Richards D, Rose A, Watkins J. Medical students in general practice: how do patients feel? Br J Gen Pract. 1996; 46(407):361-2.

4. Association of American Medical Colleges. Educating Doctors to Provide High-Quality Medical Care: A Vision for Medical Education in the United States. Washington, DC: Association of American Medical Colleges; 2004.

5. Swanson AG, Anderson MB. Educating medical students. Assessing change in medical education - The road to implementation. Acad Med. 1993; 68(6):1-46.

6. Auerbach SM, Kiesler DJ, Wartella J, Rausch S, Ward KR, Ivatury R. Optimism, satisfaction with needs met, interpersonal perceptions of the healthcare team, and emotional distress in patients' family members during critical care hospitalization. Am J Crit Care. 2005; 14(3):202-10.

7. Monfredinho AR, Silva RM. Percepção dos pacientes sobre sua participação como Instrumento de Aprendizado nas aulas praticas de semiologia. ACM Arq Catarin Med. 2006; 35(3):35-41

8. Cortopassi AC; Lima MCP, Goncalves IJ. Percepção de pacientes sobre a internação em um hospital universitário: implicações para o ensino médico. Rev Bras Educ Med. 2006. Vol. 30, N.2:42-8.

9. Brescia S, Quayle J. A Percepção do Paciente em relação à visita médica num hospital-escola: um estudo exploratório. Rev Bras Educ Med. 1997; 21:39-46.

10. Sousa Ade C, Tajra Cda R, Coelho Rde S, Gomes CM, Teixeira RA. Medical learning in a private hospital: patients' and companions' perspectives. Sao Paulo Med J. 2009; 127(2):101-4

11. Hospital de Clínicas da Unicamp. Imprensa. Guidelines. Disponível em: http://www.hc.unicamp.br/imprensa/ guideline.shtml . [Capturado em 04 Set. 2013].

12. Fontanella BJB, Ricas J, Turato ER. [Saturation sampling in qualitative health research: theoretical contributions.]. Cad Saude Publica. 2008; 24(1): 17-27.

13. Turato ER. Tratado de Metodologia da Pesquisa Clínico-Qualitativa: construção teórico-epistemológica, discussão comparada e aplicação nas áreas da saúde e humanas. 5.ed. Petrópolis: Vozes; 2011.

14. Turato ER. Qualitative and quantitative methods in health: definitions, differences and research subjects. Rev Saude Publica. 2005;39(3): 507-14.

15. Turato ER, Machado AC, Silva DF, Carvalho GM, Verderosi NR, Souza TF. Research publications in the field of health: omission of hypotheses and presentation of common-sense conclusions. Sao Paulo Med J. 2006; 124(4): 228-233 
16. Fontanella BJB, Campos CJG, Turato ER. Data collection in clinical-qualitative research: use of non-directed interviews with open-ended question by health professionals. Rev Lat Am Enfermagem. 2006; 14(5): 812-20.

17. Fletcher KE, Furney SL, Stern DR. Patients speak: what's really important about bedside interactions with physician teams. J Gen Intern Med. 2003;18(Suppl I):232]

\section{AGRADECIMENTOS}

Agradeço a todos os pacientes que permitiram a realização deste estudo com sua participação, assim como a todos os demais que permitem o ensino da arte médica diariamente, sem os quais eu não teria chegado onde estou.

\section{CONTRIBUIÇÃO DOS AUTORES}

Alcir Escocia Dorigatti participou da construção do projeto, realizando revisão de literatura, coletando dados em campo, transcrevendo as entrevistas gravadas, analisando-as, discutindo resultados, redigindo o artigo final. Eliel W. Faber participou da construção do projeto, da revisão de literatura, assim como da discussão dos artigos. Celso Garcia Jr. participou da discussão dos achados e fez revisão do artigo final. Egberto Ribeiro Turato participou das diversas etapas do projeto, sendo orientador desta pesquisa junto ao Programa Institucional de Bolsas de Iniciação Científica do CNPq/Unicamp. Todos os autores aprovaram a versão final revisada deste artigo.

\section{CONFLITO DE INTERESSES}

Declarou não haver.

\section{ENDEREÇO PARA CORRESPONDÊNCIA}

Alcir Escocia Dorigatti

Departamento de Psicologia Médica e Psiquiatria

Faculdade de Ciências Médicas (Unicamp)

Rua Tessália Vieira de Camargo, 126

Cidade Universitária "Zeferino Vaz" - Campinas

CEP 13083-887 - SP

E-mail: alcir.dorigatti@gmail.com 